\title{
HOTAIR and THRIL Long Non Coding RNAs and Their Target Genes in Rheumatoid Arthritis patients
}

\author{
Engy Medhat*1, Ghada Ayeldeen ${ }^{1}$, Hanan Hosni Ahmed ${ }^{1}$, \\ Olfat Shaker ${ }^{1}$, Tamer Gheita ${ }^{2}$, Sara Salama Ashour ${ }^{1}$
}

\begin{abstract}
Background: Rheumatoid arthtritis (RA) is a chronic systemic inflammatory autoimmune disease characterized by irreversible joint damage and deformity. The aim of this study is to investigate THRIL and HOTAIR serum expression and their target genes in Egyptian RA patients and to evaluate their relationship to the clinico-pathological data.

Methods: The present study included fifty-two RA patients and fifty-six healthy controls. RA patients were classified according to DAS28 score. All subjects were subjected to full history taking and clinical examination. Quantitative real time PCR was done to estimate the expression levels of serum THRIL and HOTAIR as well as their target genes tumor necrosis factor alpha (TNF- $\alpha$ ) and metalloproteinase 2 (MMP2) were estimated by ELISA techniques.

Results: Results revealed that both THRIL and HOTAIR were statistically over expressed in RA patients compared to healthy group with p-value $<0.05$. Results showed as well that the target genes for those longnon coding RNAs, TNF- $\alpha$ and MMP-2, were also significantly higher in RA patients compared to healthy controls.
\end{abstract}

Conclusions: Both THRIL and HOTAIR associated with their target genes, can be considered as diagnostic markers for RA.

Keywords: HOTAIR, Matrix metalloproteinase 2 and tumor necrosis factor alpha, Rheumatoid arthritis, THRIL.

\section{Introduction}

Rheumatoid arthritis (RA) is a chronic autoimmune syndrome associated with several environmental, genetic and epigenetic factors which affect the articular joints contributing to cartilage and bone damage (1). RA causes a decrease in quality of life, marked physical disability and a substantial economic cost. Onset is most frequent during middle age and women are affected 2.5 times as frequent as men. The clinical expression of disease varies, ranging from mild self limiting forms to a very aggressive and rapid evolution that culminates with the destruction of the affected joint and the resulting disability (2). The etiology is still not clear (1). The pathogenesis of RA is complex and involves different cell populations related to the innate and adaptive immune response. RA primarily starts as a state of continuous activation of cells leading to autoimmunity and immune complexes in joints and other organs where it manifests (3).

Long non coding RNAs (lncRNAs) are functionally varied family of non-coding RNAs, which their functions have been detected in the last few years. LncRNAs have been involved in modifying gene expression 
through DNA epigenetic modifications, transcription, translation, immune response and disease states. The molecular mechanisms of lncRNAs are very numerous $(4,5)$. Several lncRNAs are deregulated in autoimmune diseases such as RA and systemic lupus erythematosis (SLE) leading to aberrant gene expression that may contribute to the disease progression (6). It has also been recently found to take an important part in the pathogenesis of osteoporosis (5).

Homebox antisense intergenic RNA (HOTAIR) has been demonstrated to be expressed differentially in RA. HOTAIR, the first lncRNA to be identified, was existed on chromosome 12 and has been shown to have a role in regulation of chromatin state and epigenetic mechanisms within its different target transcripts (7). Elevated levels of inflammatory mediators are associated with autoimmune diseases accompanied by chronic or repeated inflammation. Many cytokines such as interleukine 6 (IL-6) and tumour necrosis factor alpha $(\mathrm{TNF} \alpha)$ play an important role in RA and SLE diseases (2).

TNF and heterogeneous nuclear RNPL (hnRNPL)-related immunoregulatory lincRNA(THRIL) was identified in macrophages as a lncRNA that could form a complex with hnRNPL within the nucleoplasm. The long noncoding RNA THRIL regulates the expression of TNF- $\alpha$ through its interaction with hnRNPL (8).

The aim of our study is to investigate the expression of THRIL, HOTAIR and their target genes in RA patients and to evaluate their relationship to the clinical manifestations and disease activity.

\section{Materials and Methods}

Fifty-two RA patients diagnosed according to the 2010 American College of Rheumatology (ACR)/ European League against Rheumatism (EULAR) criteria for the classification of RA (9) and were fulfilling the rules of the Declaration of Helsinki 1975. Ethical committee approval was taken from the Faculty of Medicine, Cairo University as well as written consent from each subject before the start of the study as well.

Fifty-six healthy control studies were included as well. Full history taking, clinical examinations, as well as laboratory investigations were performed on all subjects. The disease activity score (DAS28) (10) was assessed. The activity was further subgraded into mild, moderate and asevere activity as well as remission. Patients with diabetes, neoplasia, inflammatory diseases, other autoimmune diseases or receiving anti-TNF $\alpha$ were excluded from our study.

Three $\mathrm{mL}$ peripheral venous blood samples were withdrawn from each subject by using vacutainer system. Samples were collected in serum separator tubes and allowed to clot for 15 minutes, and then centrifuged at $4000 \mathrm{Xg}$ for 10 minutes. Sera were separated and stored at -80 ${ }^{\circ} \mathrm{C}$ until the time of analysis; Lnc RNA extraction and detection of the fold change for HOTAIR and THRIL expression were done using real time polymerase chain reaction (PCR) and measuring of MMP2 and TNF- $\alpha$ using ELISA techniques.

\section{Molecular Biology Techniques}

For HOTAIR and THRIL expression levels estimation in serum, RNA extraction was performed using miRNeasy mini kit and protocol for purification of serum total RNA, including non coding RNAs (Qiagen, Valencia, CA, USA). Quantitation and assessment of RNA purity was performed using the NanoDrop ${ }^{\circledR}$ (ND)-1000 spectrophotometer (NanoDrop Technologies, Inc. Wilmington, USA). Reverse transcription of LNC RNAs into complementary DNAs (cDNAs) was carried out on total RNA in a final volume of $20 \mathrm{uL}$ $\mathrm{RT}$ reactions using the miScript II RT kit (Qiagen, Valencia, CA, USA). Quantitative Real-time PCR for Detection of Lnc RNAs HOTAIR and THRIL was performed using miScript SYBR® Green PCR kit and protocol for Lnc RNAs quantitative detection (Qiagen, Valencia, CA, USA). cDNA was used as a template in a total volume of $20 \mathrm{uL}$ reaction 
with the following conditions: Initial activation step at $95^{\circ} \mathrm{C}$ for $10 \mathrm{~min}$. followed by 45 cycles of denaturation at $95^{\circ} \mathrm{C}$ for 15 sec. then $60{ }^{\circ} \mathrm{C}$ for $60 \mathrm{sec}$. After completion of the PCR cycles, melting curves analyses were performed to validate the specific generation of the expected PCR products. Glyceraldehyde

Phosphate dehydrogenase (GAPDH ) was used as an internal control. The expression levels for LNC RNAs; HOTAIR and THRIL were evaluated using the $\Delta C t$ method. The cycle threshold $(C t)$ value is the number of qPCR cycles required for the fluorescent signal to cross a specified threshold. $\Delta C t$ was calculated by subtracting the $C t$ values of GAPDH from those of target LNC RNAs. $\Delta \Delta C t$ was calculated by subtracting the $\Delta C t$ of the control samples from the $\Delta C t$ of the disease samples. The fold change in HOTAIR and THRIL expression was calculated by the equation $2^{-\Delta \Delta C t}$.

For determination of TNF alpha and MMP-2 in serum, Enzyme Linked ImmunoSorbant Assay (ELISA) kits and protocol for quantitative detection of TNF- $\alpha$ and MMP-2 in serum. The kits were provided from SUNLONGBIOTECH (Shanghai, China).

\section{Statistical Analysis}

Data Analysis was performed using the statistical package of social science (SPSS 17.0) on windows 8.1. For quantitative parametric data, an independent student t-test was used to compare measures of 2independent groups as well a One-way ANOVA test was used for comparing more than 2-independent groups with Benferroni Post-Hoc to test significance at $\mathrm{p}$-value $<0.05$.
While for quantitative nonparametric data, the Kruskal-Wallis test and Mann-Whitney test were used to compare more than 2independent groups. For measuring the correlation between qualitative data, Bivariate Pearson correlation test to find out the association between different groups with a two-tailed to test the significance. Sensitivity and specificity tests were generated for testing a new test with ROC Curve (Receiver Operating Character). Pvalue $<0.05$ was considered as a cutoff value for significance.

\section{Results}

There were 52 RA subjects with a mean age of $(39.52 \pm 10.8)$. The study included 56 aged healthy control (41.07 \pm 11.18 years). Results showed that there was not statistically significant between the two groups with respect to age and gender with p-values of 0.47 and 0.733 , respectively (Table 1 ).

RA patients were classified according to DAS28 score into inactive (Remission) (23 patients) and active (29 patients). The active patients were subdivided into mild/low (5 patients), moderate (18 patients), and severe/High (6 patients).

As regards to the activity of RA, results show that there is a highly statistically significance between DAS28 and the activity of the disease with p-value 0.001 . There is not statistically significance between disease activity $(39.93 \pm 11.08)$ and remission (39.5 \pm 10.8$)$ with p-value 0.73 . There is also not statistically significance between the disease activity and the duration of RA where p-value> 0.05 (Table 2).

Table 1. Demographic data of rheumatoid arthritis patients and control groups.

\begin{tabular}{lcccc}
\hline \multicolumn{2}{c}{ Clinical Data } & $\begin{array}{c}\text { RA } \\
\mathbf{n = 5 2}\end{array}$ & $\begin{array}{c}\text { Control } \\
\mathbf{n = 5 6}\end{array}$ & p-value \\
\hline \multirow{2}{*}{ Age (years) } & & $39.52 \pm 10.80$ & $41.07 \pm 11.18$ & 0.47 \\
\cline { 1 - 4 } Sex & Female & $44(84.5 \%)$ & $46(82 \%)$ & \multirow{2}{*}{0.733} \\
\cline { 2 - 4 } & Male & $8(15.5 \%)$ & $10(18 \%)$ & \\
\hline
\end{tabular}


Table 2. Comparison of the age, disease duration, and DAS28 according to the disease activity and inactivity in RA patients.

\begin{tabular}{|c|c|c|c|}
\hline \multirow{2}{*}{ Variables } & \multicolumn{2}{|c|}{$\begin{array}{c}\text { DAS28 Score in RA Patients }(n=52) \\
\text { Mean } \pm \text { SD }\end{array}$} & \multirow{2}{*}{ p-value } \\
\hline & $\begin{array}{c}\text { Remission } \\
(\mathrm{n}=23)\end{array}$ & $\begin{array}{l}\text { Active } \\
(\mathbf{n}=29)\end{array}$ & \\
\hline DAS28 & $1.5 \pm 0.5$ & $4.27 \pm 1.15$ & $0.001 *$ \\
\hline Age (Years) & $39.5 \pm 10.8$ & $39.93 \pm 11.08$ & 0.73 \\
\hline Disease Duration (Years) & $7.00 \pm 5.06$ & $6.56 \pm 3.89$ & 0.06 \\
\hline
\end{tabular}

* Significant at p-value <0.05, DAS28: Disease Activity Score in 28 joints.

As regards to the laboratory investigations, results shows that there was a significant increase in the mean levels of ESR and TLC in RA patients compared to the control group $(p<0.001)$. There was a significant decrease in
$\mathrm{Hb}$ value in RA patients compared to the control group $(p=0.023)$. No significant difference was detected in platelet count $(\mathrm{p}=$ $0.149)$, ALT $(p=0.06)$ and Creatinine $(p=$ 0.25 ) levels (Table 3 ).

Table 3. Laboratory investigations of RA and control groups.

\begin{tabular}{|c|c|c|c|}
\hline Variables & $\begin{array}{l}\text { RA }(n=52) \\
\text { Mean } \pm \text { SD }\end{array}$ & $\begin{array}{c}\text { Control }(n=56) \\
\text { Mean } \pm \text { SD }\end{array}$ & p-value \\
\hline $\operatorname{ESR}\left(1 m m / 1^{s t} h r\right)$ & $41.79 \pm 23.79$ & $7.5 \pm 2.37$ & $<0.001 *$ \\
\hline $\mathrm{Hb}(g m / d L)$ & $11.72 \pm 1.546$ & $12.4 \pm 1.6$ & $0.023^{*}$ \\
\hline $\operatorname{TLC}\left(x 103 / \mathrm{mm}^{3}\right)$ & $7.67 \pm 2.37$ & $6.13 \pm 1.46$ & $<0.001^{*}$ \\
\hline $\operatorname{PLT}\left(x\right.$ 103/mm $\left.{ }^{3}\right)$ & $322.12 \pm 291.76$ & $264.2 \pm 58.0$ & 0.149 \\
\hline $\operatorname{ALT}(U / m l)$ & $29.77 \pm 22.98$ & $23.9 \pm 6.0$ & 0.06 \\
\hline $\mathrm{Cr}(m g / d L)$ & $0.93 \pm 0.816$ & $0.8 \pm 0.2$ & 0.25 \\
\hline
\end{tabular}

ESR: erythrocyte sedimentation rate, Hb: hemoglobin, TLC: total leucocytic count, Pl: platelets, ALT: alanine tranaminase, Cr.: creatinine.

\section{Serum biomarkers level in $R A$ patients and \\ control group}

TNF- $\alpha$ and MMP-2 expressions were assessed in serum regarding RA group compared to healthy controls. Both expressions were highly statistically significant with a p-value of 0.001 each (Fig. 1).
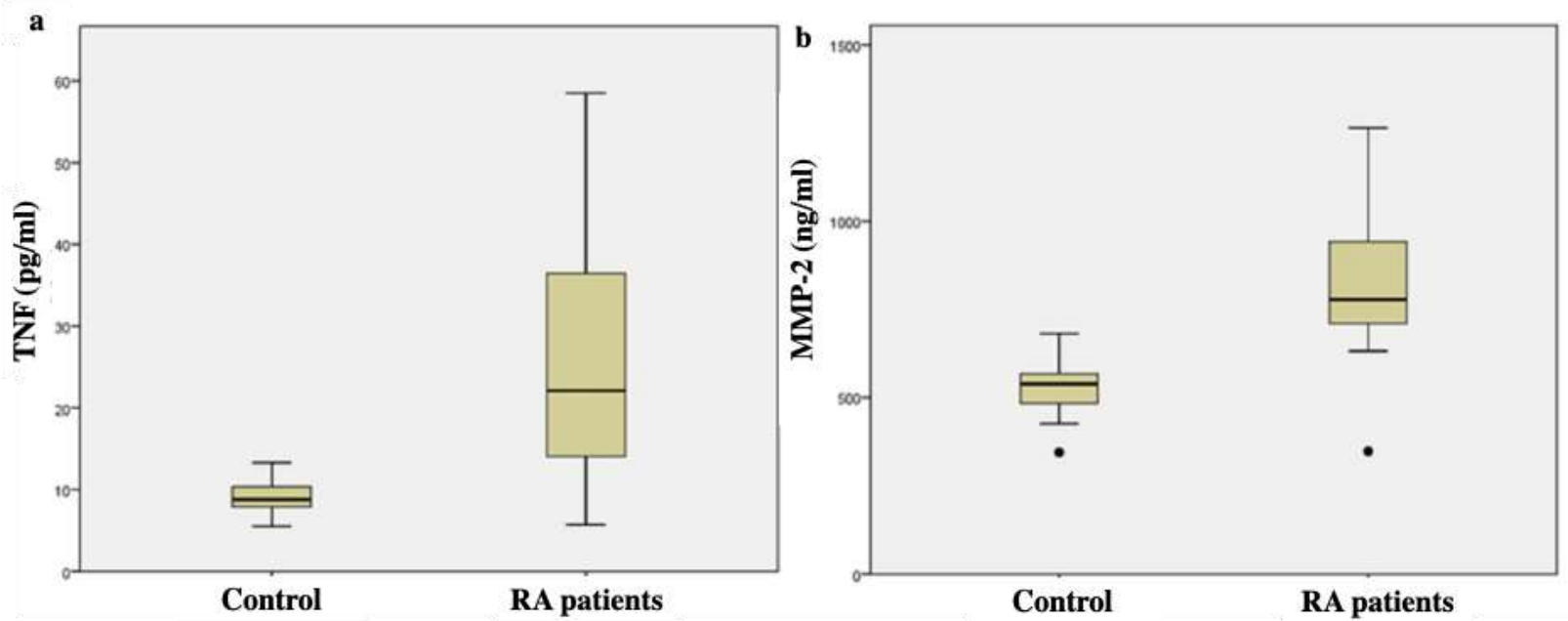

Fig. 1. Relative serum expression of (a) TNF- $\alpha$ (b) and MMP-2 among RA patients and control group. 
Furthermore, Long Non-Coding THRIL and HOTAIR fold changes in RA patients and control groups were assessed. Results revealed that the relative expressions of Long NonCoding THRIL and HOTAIR were significantly higher in RA patients compared to the control group $(\mathrm{p}=0.001)$. The relative expression of THRIL and HOTAIR tended to increase in RA patients with a 3.66- and 15.72-fold change, respectively (Fig. 2).

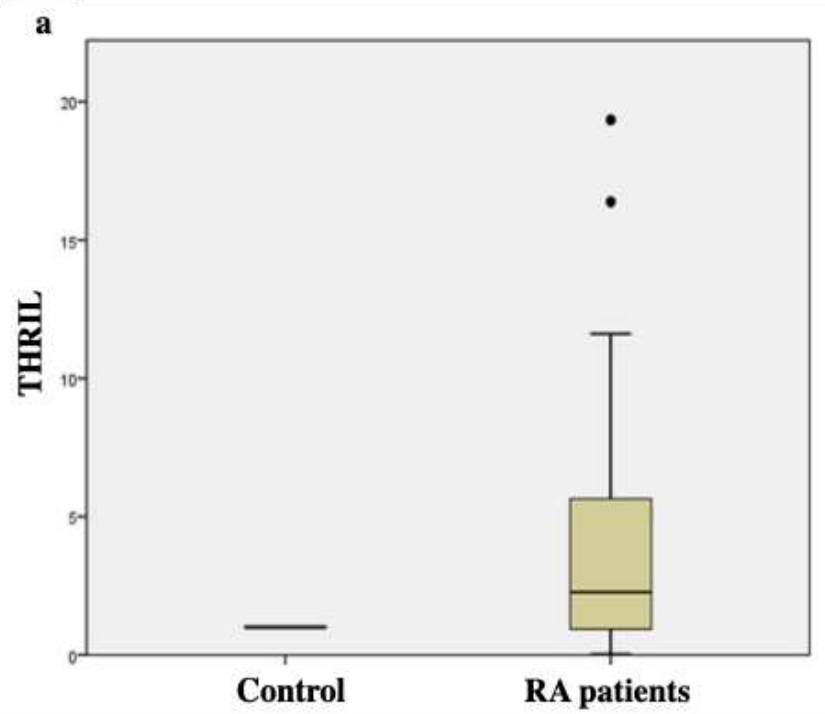

b

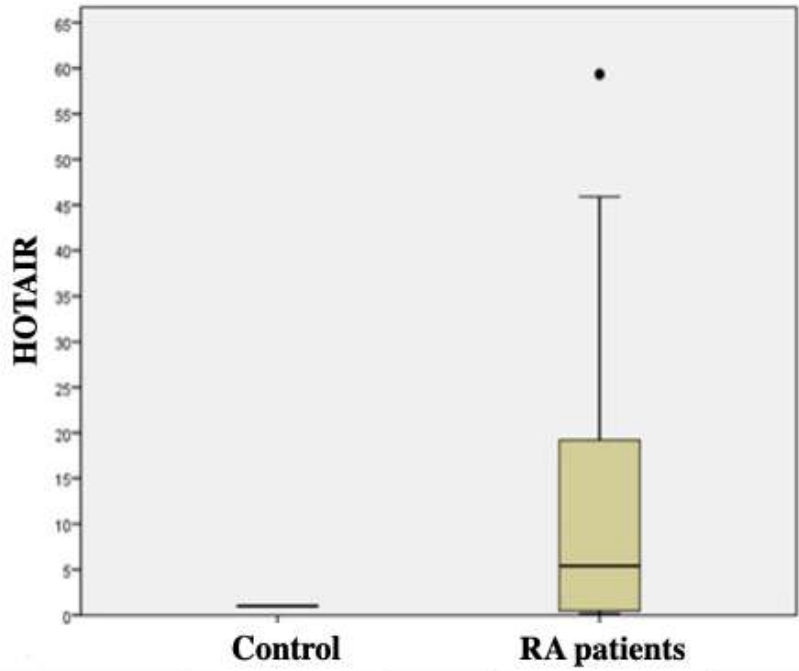

Fig. 2. Relative long-non coding serum expression of (a) THRIL and (b) HOTAIR among RA patients and control group.

Relation of DAS Score to TNF- $\alpha, M M P-2$, THRIL and HOTAIR in RA patients

After classifying the data according to DAS28 score and activity, results showed that there is statistically significant difference between TNF$\alpha$ and DAS28 score as regard to activity with p- value 0.013 . There is also statistically significant as regard to activity and MMP-2 with p-value 0.005 . There is not statistically significant difference as regards to activity and fold change of THRIL and HOTAIR with p-value> 0.05 (Table 4).

Table 4. Relation of DAS Score to TNF- $\alpha$, MMP-2, THRIL and HOTAIR in RA patients.

\begin{tabular}{cccc}
\hline \multirow{2}{*}{ Variables } & \multicolumn{2}{c}{ DAS28 Score in RA Patients $(\mathbf{n = 5 2 )}$} \\
& \multicolumn{2}{c}{$\begin{array}{c}\text { Remission } \\
(\mathbf{n}=\mathbf{2 3})\end{array}$} & p-value \\
\cline { 2 - 3 } & $17.17 \pm 1.902$ & $\begin{array}{c}\text { Active } \\
(\mathbf{n}=\mathbf{2 9})\end{array}$ & \\
\hline TNF- $\alpha$ & $709.61 \pm 8.20$ & $32.84 \pm 2.66$ & $0.013^{*}$ \\
MMP-2 & $3.93 \pm 0.76$ & $931.97 \pm 32.68$ & $0.005^{*}$ \\
THRIL & $19.75 \pm 5.62$ & $3.44 \pm 0.802$ & 0.718 \\
HOTAIR & & $12.52 \pm 3.83$ & 0.190 \\
\hline
\end{tabular}

According to TNF- $\alpha$ and DAS28 score and fold change of THRIL with DAS28 score, there is no correlation between them where $p$ value>
0.05, while there is correlation between DAS28 score activity of RA disease and MMP-2 as well as LNC HOTAIR with p-value 0.001 and 0.024 respectively (Table 5). 
Table 5. Relation of disease severity to TNF- $\alpha$, MMP-2, THRIL and HOTAIR in RA patients.

\begin{tabular}{lccccc}
\hline \multirow{2}{*}{ Parameters } & \multicolumn{3}{c}{$\begin{array}{c}\text { DAS28 Score in RA Patients }(\mathbf{n}=\mathbf{5 2}) \\
\text { Mean } \pm \text { SEM }\end{array}$} & \multirow{2}{*}{ p-value } \\
\cline { 2 - 5 } & $\begin{array}{c}\text { Remission } \\
(\mathbf{n = ~ 2 3 )}\end{array}$ & $\begin{array}{c}\text { Mild/low } \\
(\mathbf{n}=\mathbf{5})\end{array}$ & $\begin{array}{c}\text { Moderate } \\
(\mathbf{n}=\mathbf{1 8})\end{array}$ & $\begin{array}{c}\text { Severe/High } \\
(\mathbf{n}=\mathbf{6})\end{array}$ & \\
\hline TNF- $\boldsymbol{\alpha}$ & $17.17 \pm 1.902$ & $28.38 \pm 3.01$ & $29.13 \pm 3.31$ & $47.67 \pm 4.35$ & 0.395 \\
MMP-2 & $709.61 \pm 8.20$ & $769.40 \pm 6.90$ & $900.33 \pm 33.73$ & $1162 \pm 40.65$ & $0.001^{*}$ \\
THRIL & $3.93 \pm 0.76$ & $2.05 \pm 1.13$ & $4.01 \pm 1.15$ & $2.91 \pm 1.58$ & 0.895 \\
HOTAIR & $19.75 \pm 5.62$ & $11.47 \pm 6.56$ & $15.81 \pm 5.79$ & $3.54 \pm 1.89$ & $0.024^{*}$ \\
\hline
\end{tabular}

Relationship between serum TNF- $\alpha$ and MMP2 levels and clinical manifestations of $R A$ patients

Serum TNF- $\alpha$ and MPP-2 levels were significantly higher $(\mathrm{p}=0.016$ and $\mathrm{p}=0.035$, respectively) in RA patients with morning stiffness $\geq 30$ mins than RA patients with morning stiffness $<30$ mins. In addition, RA patients suffering from arthritis had significantly $(\mathrm{p}=0.029)$ higher serum levels of MMP-2. Disease duration, presence of deformities, fever, rheumatic nodules, and RF positivity, showed no statistically significant difference as regards serum TNF- $\alpha$ and MMP-2 levels. There is highly statistically significant between VAS and MMP2 with p-value 0.004 (Table 6).

Table 6. Serum TNF- $\alpha$ and MMP-2 levels in relation to the clinical manifestations of RA patients.

\begin{tabular}{|c|c|c|c|c|c|}
\hline Variables & & $\begin{array}{c}\text { TNF- } \alpha \\
\text { Mean } \pm \text { SD }\end{array}$ & p-value & $\begin{array}{c}\text { MMP-2 } \\
\text { Mean } \pm \text { SD }\end{array}$ & p-value \\
\hline \multirow{2}{*}{$\begin{array}{c}\text { Disease Duration } \\
\text { (Years) }\end{array}$} & $\leq 5$ & $24.88 \pm 15.56$ & \multirow{2}{*}{0.586} & $862.38 \pm 159.92$ & \multirow{2}{*}{0.832} \\
\hline & $>5$ & $26.60 \pm 13.98$ & & $814.13 \pm 182.11$ & \\
\hline \multirow{2}{*}{$\begin{array}{l}\text { Morning Stiffness } \\
\text { (Min) }\end{array}$} & $<30$ & $24.33 \pm 12.20$ & \multirow[t]{2}{*}{$0.016 *$} & $775.13 \pm 131.41$ & \multirow[t]{2}{*}{$0.035^{*}$} \\
\hline & $\geq 30$ & $28.05 \pm 17.25$ & & $913.36 \pm 194.24$ & \\
\hline \multirow{2}{*}{ Arthritis } & Yes & $27.04 \pm 15.07$ & \multirow[t]{2}{*}{0.280} & $860.49 \pm 185.52$ & \multirow[t]{2}{*}{$0.029 *$} \\
\hline & No & $21.67 \pm 11.86$ & & $733.45 \pm 43.60$ & \\
\hline \multirow{2}{*}{ Deformities } & Yes & $27.54 \pm 14.90$ & \multirow[t]{2}{*}{0.669} & $857.59 \pm 190.78$ & \multirow[t]{2}{*}{0.103} \\
\hline & No & $22.81 \pm 13.63$ & & $788.33 \pm 127.89$ & \\
\hline \multirow{2}{*}{ Fever } & Yes & $20.77 \pm 13.03$ & \multirow[t]{2}{*}{0.330} & $718.67 \pm 179.52$ & \multirow[t]{2}{*}{0.544} \\
\hline & No & $26.98 \pm 14.72$ & & $857.67 \pm 164.31$ & \\
\hline \multirow{2}{*}{ Rheumatoid Nodule } & Yes & $19.83 \pm 10.52$ & \multirow[t]{2}{*}{0.073} & $738.90 \pm 176.67$ & \multirow[t]{2}{*}{0.546} \\
\hline & No & $27.35 \pm 15.05$ & & $856.17 \pm 167.01$ & \\
\hline \multirow{2}{*}{ Rheumatoid Factor } & Yes & $25.98 \pm 13.77$ & \multirow[t]{2}{*}{0.814} & $838.89 \pm 179.06$ & \multirow[t]{2}{*}{0.074} \\
\hline & No & $23.42 \pm 15.18$ & & $790.85 \pm 117.43$ & \\
\hline \multirow{2}{*}{ VAS } & $\leq 5$ & $27.61 \pm 15.34$ & \multirow[t]{2}{*}{0.251} & $873.97 \pm 193.91$ & \multirow[t]{2}{*}{$0.004 *$} \\
\hline & $>5$ & $22.68 \pm 12.57$ & & $757.39 \pm 89.04$ & \\
\hline \multirow{2}{*}{ TJC } & $\leq 12$ & $30.94 \pm 4.64$ & \multirow[t]{2}{*}{0.452} & $900.50 \pm 57.59$ & \multirow[t]{2}{*}{0.297} \\
\hline & $>12$ & $24.39 \pm 2.19$ & & $813.55 \pm 25.67$ & \\
\hline \multirow{2}{*}{ SJC } & $\leq 12$ & $36.82 \pm 4.90$ & \multirow[t]{2}{*}{0.174} & $961.18 \pm 55.92$ & \multirow[t]{2}{*}{0.508} \\
\hline & $>12$ & $22.98 \pm 1.98$ & & $799.39 \pm 24.25$ & \\
\hline
\end{tabular}


Relationship between serum THIRL and HOTAIR levels and clinical manifestations of $\boldsymbol{R A}$ patients

Table 7 shows that in RA patients with a disease duration> 5 years, there was a significant $(\mathrm{p}=0.049)$ increase in the mean levels of THRIL fold change. While, the mean levels of HOTAIR fold change where significantly higher $(\mathrm{p}=0.001)$ in RA patients with a disease duration $\leq 5$ years. In patients with morning stiffness $<30$ mins, the mean levels of HOTAIR fold changes where significantly increased $(p=0.006)$. Also, the mean levels of THRIL fold change where significantly higher in patients with deformities and rheumatoid nodules $(p=0.05$ and $\mathrm{p}=0.001)$, respectively. In addition, the mean levels of HOTAIR fold change where significantly increased $(\mathrm{p}=0.032)$ in patients who were rheumatoid factor positive.

Table 7. THRIL and HOTAIR fold change in relation to the clinical manifestations in RA patients.

\begin{tabular}{|c|c|c|c|c|c|}
\hline Variables & & $\begin{array}{c}\text { THRIL } \\
\text { (Fold change) } \\
\text { Mean } \pm \text { SD }\end{array}$ & p-value & $\begin{array}{c}\text { HOTAIR } \\
\text { (Fold change) } \\
\text { Mean } \pm \text { SD }\end{array}$ & p-value \\
\hline \multirow{2}{*}{$\begin{array}{l}\text { Disease Duration } \\
\text { (Years) }\end{array}$} & $\leq 5$ & $2.86 \pm 2.43$ & \multirow[t]{2}{*}{$0.049^{*}$} & $23.76 \pm 30.55$ & \multirow[t]{2}{*}{$0.001 *$} \\
\hline & $>5$ & $4.20 \pm 4.75$ & & $10.27 \pm 15.93$ & \\
\hline \multirow{2}{*}{$\begin{array}{l}\text { Morning Stiffness } \\
\text { (Min) }\end{array}$} & $<30$ & $3.59 \pm 3.42$ & \multirow[t]{2}{*}{0.236} & $20.63 \pm 28.06$ & \multirow[t]{2}{*}{$0.006^{*}$} \\
\hline & $\geq 30$ & $3.75 \pm 4.77$ & & $9.03 \pm 13.83$ & \\
\hline \multirow[t]{2}{*}{ Arthritis } & Yes & $4.08 \pm 4.26$ & \multirow[t]{2}{*}{0.207} & $14.27 \pm 22.02$ & \multirow[t]{2}{*}{0.163} \\
\hline & No & $2.10 \pm 2.43$ & & $21.42 \pm 29.57$ & \\
\hline \multirow[t]{2}{*}{ Deformities } & Yes & $4.26 \pm 4.57$ & \multirow[t]{2}{*}{$0.05 *$} & $14.42 \pm 23.79$ & \multirow[t]{2}{*}{0.786} \\
\hline & No & $2.52 \pm 2.33$ & & $16.30 \pm 24.09$ & \\
\hline \multirow[t]{2}{*}{ Fever } & Yes & $2.66 \pm 2.41$ & \multirow[t]{2}{*}{0.228} & $13.23 \pm 28.91$ & \multirow[t]{2}{*}{0.992} \\
\hline & No & $3.87 \pm 4.25$ & & $16.24 \pm 22.78$ & \\
\hline \multirow[t]{2}{*}{ Rheumatoid Nodule } & Yes & $6.79 \pm 6.72$ & \multirow[t]{2}{*}{$0.001 *$} & $14.25 \pm 15.14$ & \multirow[t]{2}{*}{0.270} \\
\hline & No & $2.91 \pm 2.66$ & & $16.07 \pm 25.411$ & \\
\hline \multirow[t]{2}{*}{ Rheumatoid Factor } & Yes & $3.80 \pm 3.73$ & \multirow[t]{2}{*}{0.961} & $18.51 \pm 26.74$ & \multirow[t]{2}{*}{$0.032 *$} \\
\hline & No & $3.63 \pm 5.01$ & & $9.33 \pm 12.23$ & \\
\hline \multirow[t]{2}{*}{ VAS } & $\leq 5$ & $3.37 \pm 0.69$ & \multirow[t]{2}{*}{0.777} & $13.85 \pm 3.46$ & \multirow[t]{2}{*}{0.148} \\
\hline & $>5$ & $4.19 \pm 0.94$ & & $19.25 \pm 6.94$ & \\
\hline \multirow[t]{2}{*}{ TJC } & $\leq 12$ & $3.53 \pm 0.89$ & \multirow[t]{2}{*}{0.511} & $21.19 \pm 7.49$ & \multirow[t]{2}{*}{0.434} \\
\hline & $>12$ & $3.70 \pm 0.67$ & & $14.08 \pm 3.64$ & \\
\hline \multirow[t]{2}{*}{ SJC } & $\leq 12$ & $3.52 \pm 1.05$ & \multirow[t]{2}{*}{0.955} & $22.38 \pm 8.78$ & \multirow[t]{2}{*}{0.107} \\
\hline & $>12$ & $3.70 \pm 0.65$ & & $13.93 \pm 3.44$ & \\
\hline
\end{tabular}


Correlations TNF- $\alpha, M M P-2$ and clinical manifestations of $R A$ patients

As regard to the morning stiffness the number of patients have morning stiffness $>30$ minutes are $\mathrm{n}=15$ where there is positive correlation with TNF- $\alpha$ with patients having MS> $30 \mathrm{~min}$. While there is negative correlation between morning stiffness and TNF- $\alpha$ with $r=-0.330$ and $p$-value $=$ 0.016 for patients having MS $<30 \mathrm{~min} \mathrm{n}=37$. There is also a positive correlation between morning stiffness and MMP-2 with $\mathrm{r}=-0.177$ and $\mathrm{p}$-value 0.035 . there is positive correlation between SJC and TNF- $\alpha$ and MMP-2 with ( $\mathrm{r}=$ 0.57 and $p$-value $=0.0001)$ and $(r=0.61$ and $p$ value $=0.0001)$ respectively. There was also a positive correlation between both TNF and TJC and between MMP-2 and TJC with $(r=0.63$ and $\mathrm{p}$-value $=0.0001)$ and $(r=0.64$ and $p$-value $=$ 0.0001 ) respectively.

\section{Correlations THRIL, HOTAIR and clinical manifestations of $R A$ patients}

Results showed that there was a statistically negative significant correlation between morning stiffness and LNC THRIL fold change $(\mathrm{r}=-0.02$ and $\mathrm{p}$-value $=0.049)$. As well as a negative significant correlation between morning stiffness and LNC THRIL fold change $(\mathrm{r}=-0.20$ and $\mathrm{p}$-value $=0.001)$. There was no correlation between ESR and THIRL nor between HOTAIR and ERS.

\section{Correlations all serum biomarkers}

There was a positive correlation between TNF- $\alpha$ and MMP-2 in RA patient groups with $r=0.788$ and $\mathrm{p}$-value 0.0001 . There was also a positive correlation between THRIL and HOTAIR fold change in RA patient groups with $r=0.29$ and $p$ value 0.0369 (Fig. 3).
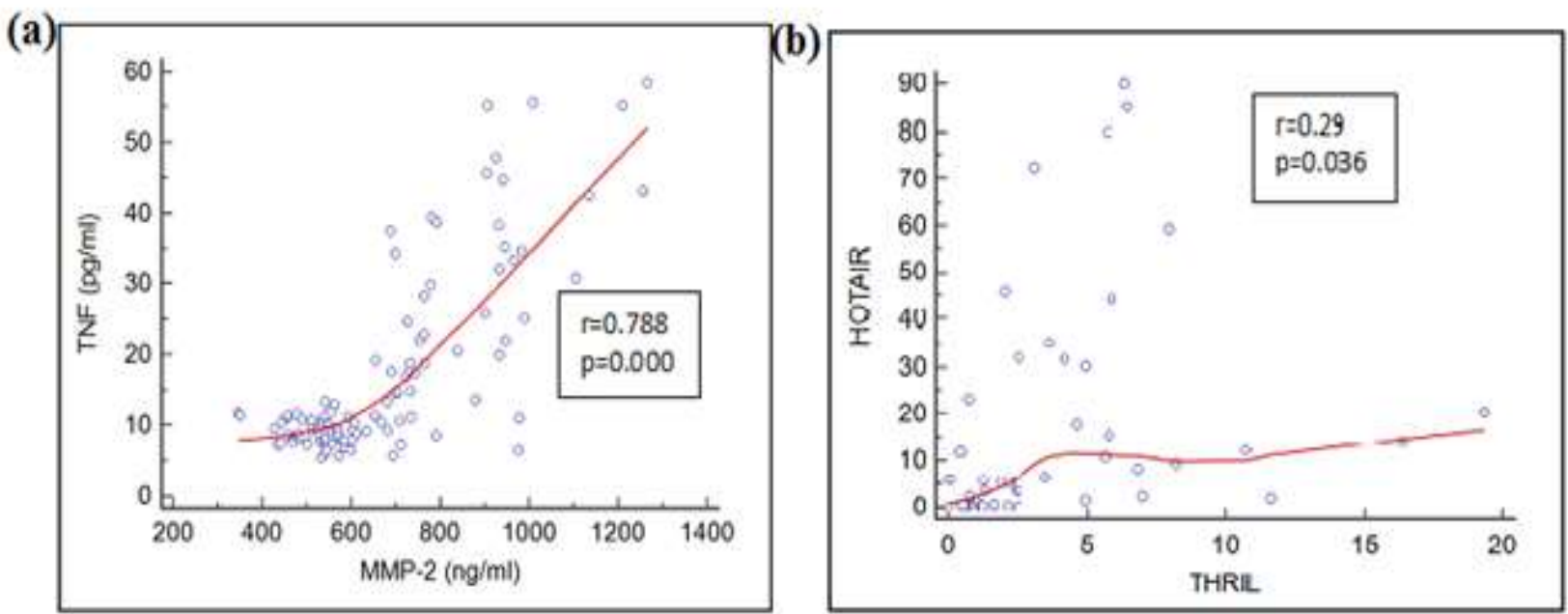

Fig. 3. Correlation between (a) TNF- $\alpha$ and MMP-2 (b) THRIL and HOTAIR fold change in RA patients.

\section{ROC curve analysis for serum biomarkers}

The ROC curve analysis of serum TNF- $\alpha$, MMP-2, THRIL and HOTAIR for RA patients is determined in Fig.4. Diagnostic performance of different genes expression as markers of RA group at different cutoff points using (ROC) curve. For discrimination of RA group versus control group, regarding TNF- $\alpha$, the $\mathrm{AUC}=0.90$ with a sensitivity of $78.8 \%$ and specificity of $98.2 \%$, while for MMP-2, the AUC was of 0.98 with a sensitivity of $98.0 \%$ and specificity of $98.21 \%$ (Fig. 4 ).

Regarding lnc THRIL and HOTAIR, (AUC $=$ 0.73 with a sensitivity of $73.08 \%$ and specificity of $100 \%)$ and $(\mathrm{AUC}=0.69$ with a sensitivity of $61.58 \%$ and specificity of $100 \%$ ) respectively (Fig. 5). 

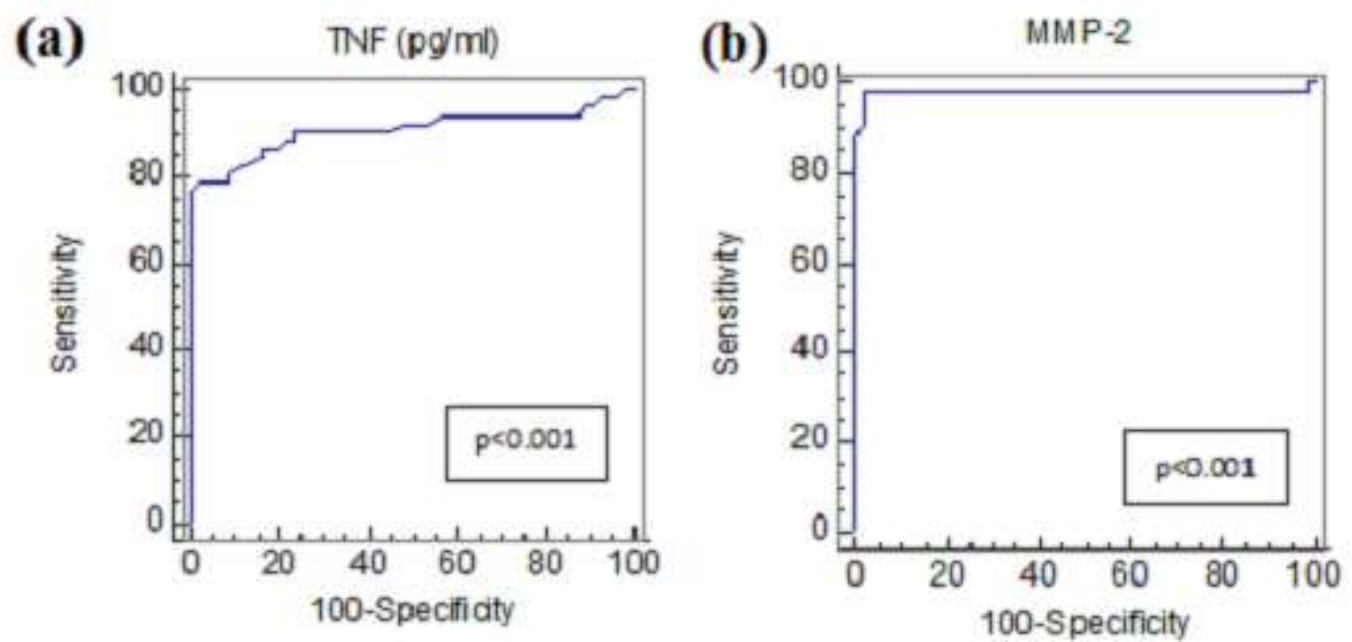

Fig. 4. ROC curve for (a) TNF- $\alpha$ (b) MMP-2 in RA patients group.
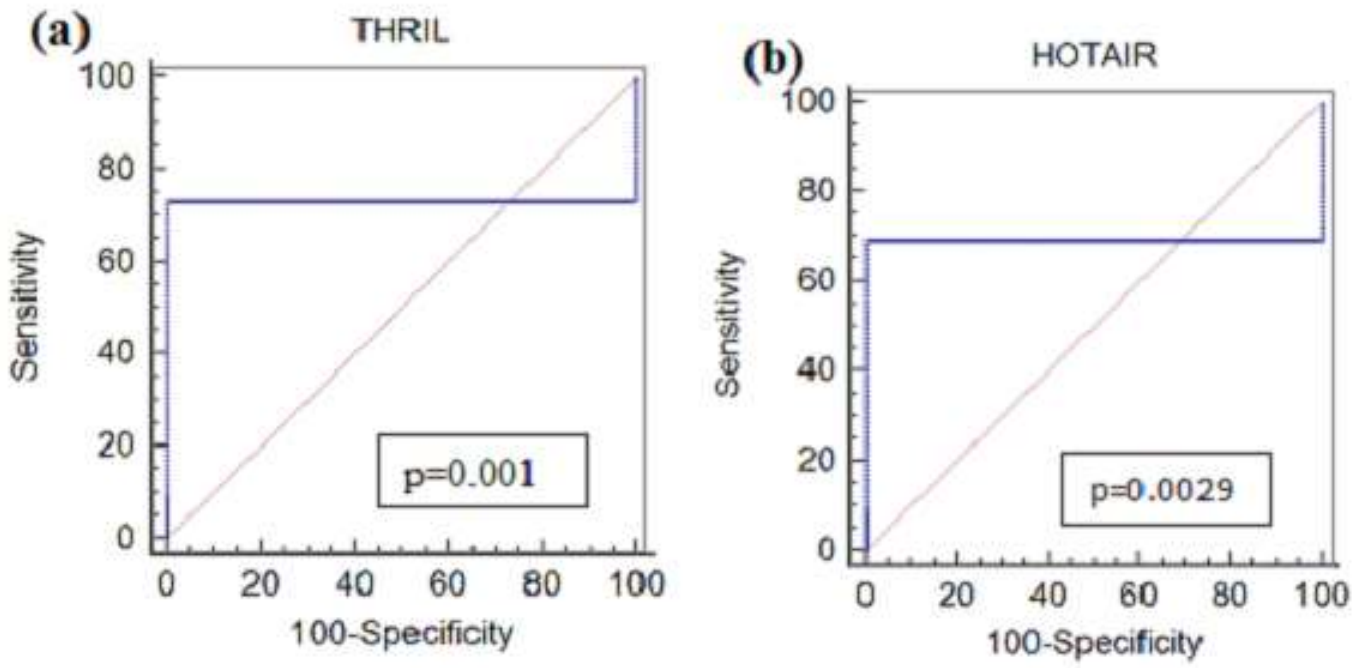

Fig. 5. ROC curve for (a) THRIL (b) HOTAIR in RA patients group.

\section{Discussion}

Rheumatoid arthritis is a common systemic and autoimmune disease in which the pathophysiology underlying its development and progression is a result of dysregulations of the immune system (11). Its primary pathological characters are synovitis and vasculitis. A critical role of non-coding RNAs (ncRNAs) in inflammation and autoimmune regulation, primarily including microRNA (miRNA), long non-coding RNA (lncRNA), and circular RNA (circRNA) has been implicated (12). RA is characterized by destruction of cartilage and bones as well as consistent synovitis leading to multiple joints deformities (13). It is also characterized by hyperplasia, autoantibody production and systemic features. Chronic inflammation and bone erosion are the central characteristics of RA $(14,15)$. Chronic inflammation in RA is caused by the imbalance between cytokines of pro- and anti-inflammation and the induction of autoimmunity (16).

Potential triggers of RA include autoantibodies such as ACPA and rheumatoid triggers, and pro-inflammatory cytokines like TNF- $\alpha$ and IL-6 (16). TNF- $\alpha$, particularly, plays a pivotal role in the pathogenesis of RA. In rheumatoid synovial tissue TNF- $\alpha$ is the principal cytokine which regulates the formation of other pro-inflammatory cytokines (17). Production of connective tissue growth factor is mediated by the activation of synovial 
fibroblasts by TNF- $\alpha$. This in turn promotes the hyperactivation of osteoclasts and thus the destruction of joints (18). In the present study, serum TNF- $\alpha$ levels were significantly higher in patients than the control. Moreover, it was significantly higher in active patients than in remission. The present work agrees with others (19-21) reporting an elevation of serum TNF- $\alpha$ in RA. On the contrary, Ebrahimi et al found no significant differences in serum level of TNF- $\alpha$ between RA patients and the control (22).

Rheumatoid arhritis is characterized by progressive joint destruction with loss of bone and cartilage as well as the aggressive activation of synovial fibroblasts (SFs) bearing a tumor-like appearance $(23,24)$. MMPs play a critical role in the pathogenesis of RA. RA SFs secrete various proteases, including MMPs that degrade ECM components, mainly proteoglycans and collagens, of articular cartilage in the affected joints (25). MMP-2 (gelatinase A) is important in collagen degradation, through digestion of denatured collagen (gelatin), generated by collagenases. Additionally, it digests other substrates, including fibrillar collagen I and II and aggrecan, which predominantly exist in cartilage (26). In the present study, serum MMP-2 levels were significantly high in patients especially those with activity. In harmony, Giannelli et al. and Chang et al. reported a significant increase in MMP-2 in RA patients $(27,28)$.

Initiation and development of RA is influenced by both environmental and genetic factors. It has been postulated that a high-risk genetic background, together with epigenetic elements and environmental exposures, leads to a cascade of events initiating RA (29). The ncRNAs involved in epigenetic mechanisms are divided into two principal subgroups: the lncRNAs with more than 200 nucleotides and small ncRNAs with less nucleotides (30). Thousands of lncRNAs have been identified and they play an important role in regulation of the gene expression (31). Functions assigned to lncRNAs include transcriptional interference, initiation of chromatin remodeling, promoter inactivation by binding to basal transcription factors, oligomerization of activator protein, activation and transport of transcription factors, activation of accessory protein and epigenetic repression of genes or gene clusters (32). Accumulating evidence has shown that lncRNAs participate in the process of inflammation, aberrant proliferation, migration, invasion and apoptosis (33) and their roles in autoimmune diseases, such as SLE, MS, RA and Sjogren's syndrome have also been demonstrated (34).

In this work, the expression of two lncRNAs was investigated; THRIL and HOTAIR. THRIL induce TNF- $\alpha$ expression and is essential in the innate immune response and inflammatory diseases (8). The expression of both were found to be significantly upregulated in serum of the RA patients. In concordance, Moharamoghli et al. indicated that $\mathrm{T}$ cells of RA patients significantly upregulate gene expression of THRIL (35). In accordance, Fouad et al. reported that THRIL was significantly upregulated in the serum of SLE patients (36). Moreover, Song et al. reported that expression of HOTAIR was upregulated in patients with RA (14). Shaker et al. who assessed the serum expression levels of HOTAIR in RA and investigated their role as novel noninvasive biomarkers in diagnosis of RA reported that HOTAIR was significantly upregulated (37).

In this work a significant correlation between THRIL and HOTAIR expression was detected in patients which indicates their role in the pathogenesis of the disease. There was a significant correlation between THRIL expression and serum TNF- $\alpha$. THRIL was recently identified in macrophages as a lncRNA that is important for the processing, function, and stabilization of mRNAs. Critically, it was demonstrated that the THRIL-hnRNPL complex binds to the promotor of TNF and induces its expression following TLR-2 activation (8). On the contrary, Moharamoghli et al. did not find a link between THRIL and TNF- $\alpha$ in RA as the sample size was very small (20 patients) (35). The characteristic inflammation of RA occurs due to the abundance of proinflammatory cytokines. 
TNF- $\alpha$ is key and regulates the formation of other inflammatory mediators in the synovial tissue such as IL-1 and MMPs, involved in its degradation (18).

In the present study, serum levels of TNF- $\alpha$ and MMP-2 showed a significant relation to the disease activity in RA patients. While, HOTAIR expression was higher in RA patients in remission. A significant negative correlation was found between HOTAIR expression and serum MMP-2 levels in patients. This coincides with Song et al., who reported that expression of HOTAIR was upregulated in PBMCs and the serum exosome of patients with RA, but conversely HOTAIR was downregulated in differentiated osteoclasts and rheumatoid synoviocytes (14). Increased HOTAIR expression might enhance the recruitment of macrophages to target tissues in RA, whereas decreased levels in osteoclasts and synoviocytes can increase MMP-2 and MMP13 expression, which disintergrate the bone and cartilage matrix and when overproduced, can lead to joint destruction. These results indicate that aberrant expression of HOTAIR is involved in the pathogenesis of RA.

A significant correlation between serum TNF- $\alpha$ and MMP-2 was found in patients. Chu et al. reported that TNF- $\alpha$ upregulates the expression of MMPs and increase MMP-9 production in all synovial and some meniscal cultures (38). Furthermore, Scian et al. reported that the main inducer of MMP-2 secretion in synoviocytes was TNF- $\alpha$ (39). A preponderant role of TNF- $\alpha$ as an MMP inducer has been determined (40).

Serum TNF- $\alpha$ and MMP-2 levels were significantly higher in patients with morning stiffness $\geq 30$ mins. MMP-2 was significantly higher in patients with VAS $\leq 5$. In addition, those with arthritis had significantly higher serum levels of MMP-2. TNF- $\alpha$ and MMP-2 significantly correlated with morning stiffness, SJC and TJC. The present work agrees partly with a study conducted by Klimiuk et al. who found that serum TNF- $\alpha$ correlated not only with ESR but also with CRP, the number of swollen joints, and the DAS (41). Others observed a significant correlation of serum TNF- $\alpha$ with the ESR, and CRP (42).

In the present study, patients with a disease duration> 5 years had a significant increase in the levels of THRIL while, HOTAIR was significantly higher in patients with a $\mathrm{DD} \leq 5$ years. In patients with morning stiffness $<30$ mins or positive RF, the HOTAIR was significantly increased. THRIL was significantly higher in patients with deformities and RN. In the present study, a significant correlation was detected between THRIL expression and ESR. On the contrary, Moharamoghli et al. observed no correlation yet their sample size was small and they are detecting mRNA expression levels of TNF- $\alpha$ not the protein level (35).

In the present study THRIL significantly predicted RA with a sensitivity $73.08 \%$ and specificity $100 \%$ at AUC 0.73; while HOTAIR at AUC 0.69 the sensitivity was $61.58 \%$ and specificity $100 \%$ suggesting that THRIL and HOTAIR may be potential diagnostic biomarkers for RA. In agreement, Shaker et al. reported that IncRNA HOTAIR could discriminate RA patients from controls (37). Also, Moharamoghli et al. reported that THRIL significantly predicted RA thus providing better diagnostic efficiency (35). Furthermore, at AUC 0.91, serum TNF- $\alpha$ predicted RA at a sensitivity of $78.8 \%$ and specificity $98.2 \%$; while MMP-2 at 0.98 the sensitivity was $98.1 \%$ and specificity $98.2 \%$ suggesting that serum TNF- $\alpha$ and MMP-2 may be potential diagnostic biomarkers for RA.

Large multicenter studies on a large population should be performed to give more accurate results about the expression variability of the studied lncRNAs among Egyptian RA patients, as well as verifying their diagnostic and prognostic values. Screening of different lncRNAs should be carried out among Egyptian RA patients to detect which are exclusively or remarkably expressed in our ethnic group. To investigate whether the expression pattern is mirrored in different specimens, further studies should be performed to compare the expression in RA synovial fluids, plasma, PBMCs or tissues. Multiple endogenous housekeeping 
genes should be tested to find the most appropriate one for data normalization. Manipulation of HOTAIR and THRILL expressions may represent a new therapy for several human diseases. TNF- $\alpha$ and MMP-2 can be used in therapy monitoring.

In conclusion, the IncRNAs, HOTAIR and THRIL contribute to the pathogenesis of RA through activation of their target genes MMP-2 and TNF- $\alpha$, respectively. Serum levels ofTNF$\alpha$ and MMP-2 were significantly higher in RA patients compared to control and they were

\section{References}

1. Fang Q, Zhou C, Nandakumar KS. Molecular and Cellular Pathways Contributing to Joint Damage in Rheumatoid Arthritis. Mediators Inflamm. 2020;2020:3830212.

2. Scott DL, Wolfe F, Huizinga TW. Rheumatoid arthritis. The Lancet. 2010;376(9746):1094-1108.

3. De Rycke L, Peene I, Hoffman IE, Kruithof E, Union A, Meheus L. Rheumatoid factor and anticitrullinated protein antibodies in rheumatoid arthritis: diagnostic value, associations with radiological progression rate, and extra-articular manifestations. Ann Rheum Dis. 2004;63(12):1587-93.

4. Pearson MJ, JonesSW. Review: long noncoding RNAs in the regulation of inflammatory pathways in rheumatoid arthritis and osteoarthritis. Arthritis Rheumatol. 2016;68(11):2575-2583.

5. Li Y, Li J, Chen L, Xu L. The roles of long non-coding RNA in osteoporosis. Curr Stem Cell Res Ther. 2020;15(7):639-645.

6. Kochi Y: Genetics of autoimmune diseases: perspectives from genome-wide association studies. Int Immunol. 2016;28(4):155-61.

7. Gupta R, Shah N, Wang K, Kim j, Hurling's $\mathrm{H}$, Wong $\mathrm{D}$, et al. Long non-coding RNA HOTAIR reprograms chromatin state to promote cancer metastasis. Nature. 2010;464(7291):1071-6.

8. Li Z, Chao TC, Chang KY, Lin N, Patil VS, Shimizu $C$, et al. The long noncoding RNA THRIL regulates TNF $\alpha$ expression through its interaction with hnRNPL. Proc Natl Acad Sci U S A. 2014;111(3):1002-7. positively correlated to some clinical manifestations of RA. LncRNAs THRIL and HOTAIR were highly over expressed in RA patients compared to control and could be used as diagnostic markers for RA.

\section{Acknowledgements}

We would like to thank members of the Medical Biochemistry Department, Faculty of medicine, Cairo University for their support. We are grateful to all our patients for their great cooperation.

9. Aletaha D, Neogi T, Silman AJ, Funovits J, Felson DT, Bingham 3rd CO, et al. 2010 Rheumatoid arthritis classification criteria: an American College of Rheumatology/European League Against Rheumatism collaborative initiative. Arthritis Rheum. 2010;69(9):2569-81.

10. Prevoo ML, van't Hof MA, Kuper HH, van Leeuwen MA, van de Putte LB, van Riel PL. Modified disease activity scores that include twenty-eight-joint counts. Development and validation in a prospective longitudinal study of patients with rheumatoid arthritis. Arthritis Rheum. 1995;38(1):44-8.

11. Ansari-Moghaddam B, Kiani AA, Sheikhian A, Birjandi M, Ahmadi SAY, Mousavi N, et al. Rheumatoid Arthritis Susceptibility Is Associated with the KIR2DS4-Full of Killer-Cell Immunoglobulin-Like Receptor Genes in the Lur Population of Iran. Rep Biochem Mol Biol. 2021;10(1):84-94.

12. Wang J, Yan S, Yang J, Lu H, Xu D, Wang Z. Non-coding RNAs in Rheumatoid Arthritis: From Bench to Bedside. Front Immunol. 2020; 10:3129.

13. Song J, Kim D, Han J, Kim Y, Lee M, Jin E. PBMC and exosome-derived HOTAIR is a critical regulator and potent marker for rheumatoid arthritis. Clin Exp Med. 2015;15(1):121-6.

14. McInnes IB, Schett G. The pathogenesis of rheumatoid arthritis. N Engl J Med. 2011;365(23):2205-19.

15. Schett G, Gravallese E. Bone erosion in rheumatoid arthritis: mechanisms, diagnosis 
and treatment. Nat Rev Rheumatol. 2012;8(11):656-64.

16. Moelants EA, Mortier A, Van Damme J, Proost P. Regulation of TNF-alpha with a focus on rheumatoid arthritis. Immunol Cell Biol. 2013;91(6):393-401.

17. Brzustewicz E, Bryl E. The role of cytokines in the pathogenesis of rheumatoid arthritis, Practical and potential application of cytokines as biomarkers and targets of personalized therapy. Cytokine. 2015;76(2):527-536.

18. Nozawa K, Fujishiro M, Takasaki Y, Sekigawa I. Inhibition of rheumatoid arthritis by blocking connective tissue growth factor. World J Orthop. 2014;5(5):653-659.

19. Milman N, Karsh J, Booth RA. Correlation of a multi- cytokine panel with clinical disease activity in patients with rheumatoid arthritis. Clin Biochem. 2010;43(16-17):1309-14.

20. Wei ST, Sun YH, Zong SH, Xiang YB Serum. Levels of IL-6 and TNF-a May Correlate with Activity and Severity of Rheumatoid Arthritis. Med Sci Monit. 2015;21:4030-4038.

21. Hadinedoushan H, Noorbakhsh P, Soleymani-Salehabad H. Tumor Necrosis Factor Alpha Gene Polymorphism and Association With Its Serum Level in Iranian Population With Rheumatoid Arthritis. Arch Rheumatol. 2016;31(4):306-313.

22. Ebrahimi AA, Noshad H, Sadreddini S, Hejazi MS, Mohammadzadeh Sadigh Y, Eshraghi Y, et al. Serum Levels of TNF- $\alpha$, TNF$\alpha$ RI, TNF- $\alpha$ RII and IL-12 in Treated Rheumatoid Arthritis Patients. Iran J Immunol. 2009;6(3):147-53.

23. Bartok B, Firestein GS. Fibroblast-like synoviocytes: Key effector cells in rheumatoid arthritis. Immunol Rev. 2010;233(1):233-55.

24. Filer A. The fibroblast as a therapeutic target in rheumatoid arthritis. Curr Opin Pharmacol. 2013;13:413-9.

25. Frisenda S, Perricone C, Valesini G. Cartilage as a target of autoimmunity: A thin layer. Autoimmun Rev. 2013;12(5):591-8.

26. Charni-Ben TN, Desmarais S, Bay-Jensen AC, Delaissé JM, Percival M D, Garnero PThe. type II collagen fragments Helix-II and CTX-II reveal different enzymatic pathways of human cartilage collagen degradation. Osteoarthritis Cartilage. 2008;16(10):1183-91.

27. Giannelli G, Erriquez R, Iannone F, Marinosci F, Lapadula G, Antonaci S. MMP-2, MMP-9, TIMP-1 and TIMP-2 levels in patients with rheumatoid arthritis and psoriatic arthritis. Clin Exp Rheumatol. 2004;22(3):335-8.

28. Chang YH, Lin IL, Tsay GJ, Yang SC, Yang TP, Ho KT, et al. Elevated circulatory MMP-2 and MMP-9 levels and activities in patients with rheumatoid arthritis and systemic lupus erythematosus. Clin Biochem. 2008;41(12):955-959.

29. Angelotti F, Parma A, Cafaro G, Capecchi R, Alunno A, Puxeddu I. One year in review 2017: pathogenesis of rheumatoid arthritis. Clin Exp Rheumatol. 2017 May-Jun;35(3):368-378.

30. Kolarz B, Majdan M. Epigenetic aspects of rheumatoid arthritis: contribution of non-coding RNAs. Seminars in Arthritis and Rheumatism. 2017;46(6):724-731.

31. Shaker O, Mahfouz H, Salama A, Medhat E. Long Non-Coding HULC and miRNA-372 as Diagnostic Biomarkers in Hepatocellular Carcinoma. Rep Biochem Mol Biol. 2020;9(2):230-240.

32. Ponting CP, Oliver PL, Reik W. Evolution and functions of long noncoding RNAs. Cell. 2009;136(4):629-41.

33. Klec C, Gutschner T, Panzitt K,Pickler M. Involvement of long noncoding RNA HULC (highly up-regulated in liver cancer) in pathogenesis and implications for therapeutic intervention. Expert Opin Ther Targets. 2019;23(3):177-186.

34. Xu F, Jin L, Jin Y, Nie Z, Zheng H. Long noncoding RNAs in autoimmune diseases. $\mathrm{J}$ Biomed Mater Res A. 2019;107(2):468-475.

35. Moharamoghli M, Hassan-Zadeh V, Dolatshahi E, Alizadeh Z, Farazmand A. The expression of GAS5, THRIL, and RMRP lncRNAs is increased in T cells of patients with rheumatoid arthritis. Clin Rheumatol. 2019;38(11):3073-3080

36. Fouad NA, Shaker OG, Mohamed EA, ElSayed HS, Hussein HA, Ahmed NA, et al. Diagnostic potential of metastasis-associatedlung-adenocarcinomatranscript-1 (MALAT-1) 
and TNFa and hnRNPL related immunoregulatory long non-coding RNA (THRIL) in systemic lupus erythematosus patients: Relation to disease activity. The Egyptian Rheumatologist. 2019;41:197-201.

37. Shaker O, Mahmoud R, Abdelaleem O, Ahmed T, Fouad N, Hussein H, et al. Expression Profile of Long Noncoding RNAs, lnc-Cox2, and HOTAIR in Rheumatoid Arthritis Patients. J Interferon Cytokine Res. 2019;39(3):174-180.

38. Chu SC, Yang SF, Lue KH, Hsieh YS, Wu $\mathrm{CL}, \mathrm{Lu} \mathrm{KH}$. Regulation of gelatinases expression by cytokines, endotoxin, and pharmacological agents in the human osteoarthritic knee. Connect Tissue Res. 2004;45(3):142-50.

39. Scian R, Barrionuevo P, Giambartolomei GH, De Simone EA, Vanzulli SI, Fossati CA, et al. Potential Role of Fibroblast-Like Synoviocytes in Joint Damage Induced by Brucella abortus Infection through Production and Induction of Matrix Metalloproteinases. Infect Immun. 2011;79(9):3619-32.
40. Wang Y, Yang L, Zhang J, Xue R, Tang Z, Huang W, et al. Differential MMP-2 activity induced by mechanical compression and inflammatory factors in human synoviocytes. Mol Cell Biomech. 2010;7(2):105-14.

41. Klimiuk PA, Sierakowski S, Latosiewicz R, Cylwik JP, Cylwik B, Skowronski J, et al. Circulating tumour necrosis factor alpha and soluble tumour necrosis factor receptors in patients with different patterns of rheumatoid synovitis. Ann Rheum Dis. 2003;62(5):472-475. 42. Manicourt DH, Triki R, Fukuda K, Devogelaer JP, Nagant de Deuxchaisnes C, Thonar EJ. Levels of circulating tumor necrosis factor a and interleukin- 6 in patients with rheumatoid arthritis. Relationship to serum levels of hyaluronan and antigenic keratan sulfate. Arthritis Rheum. 1993;36(4):490-9. 